ORNL-2969

UC-34 - Physics

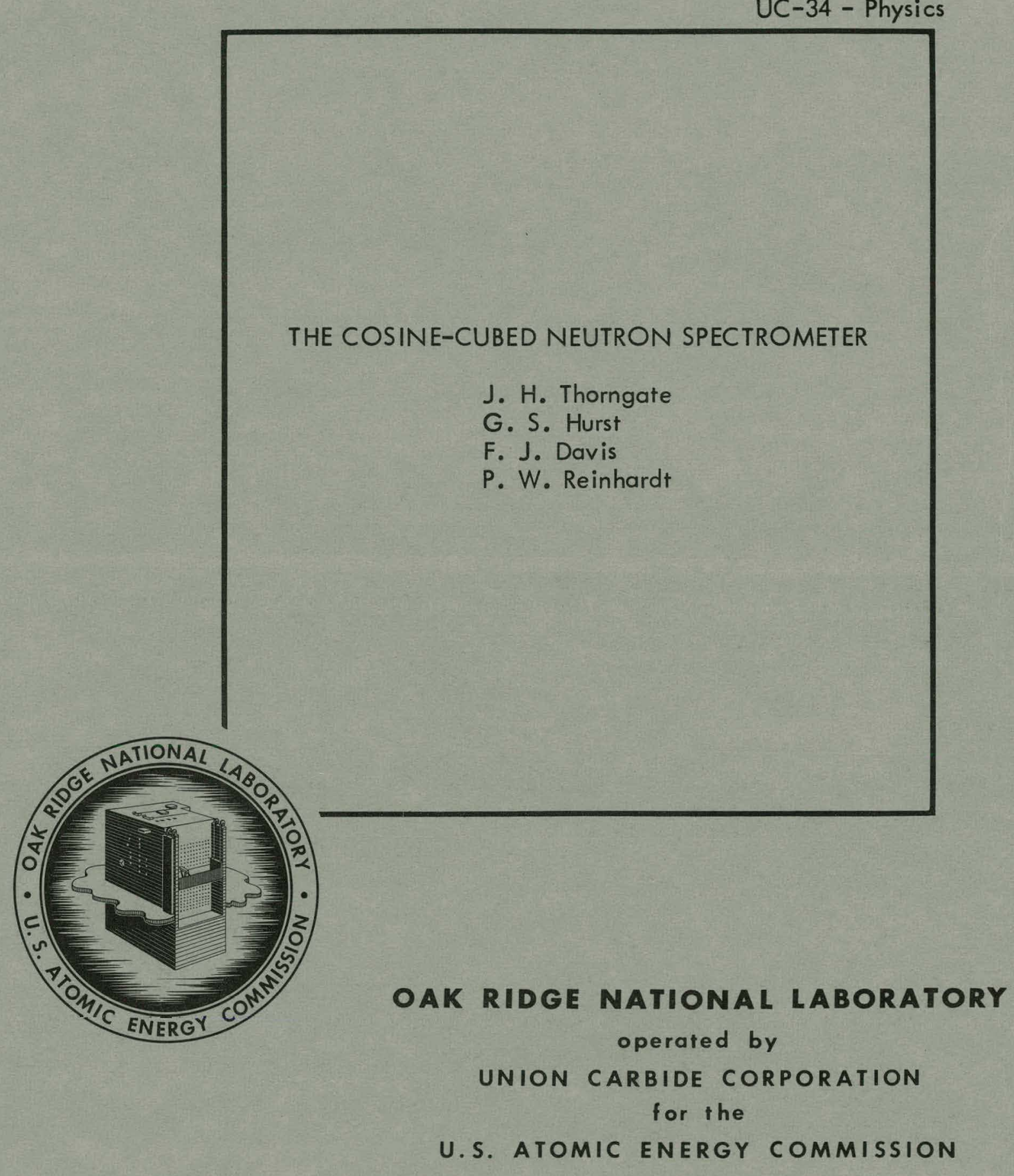




\section{DISCLAIMER}

This report was prepared as an account of work sponsored by an agency of the United States Government. Neither the United States Government nor any agency Thereof, nor any of their employees, makes any warranty, express or implied, or assumes any legal liability or responsibility for the accuracy, completeness, or usefulness of any information, apparatus, product, or process disclosed, or represents that its use would not infringe privately owned rights. Reference herein to any specific commercial product, process, or service by trade name, trademark, manufacturer, or otherwise does not necessarily constitute or imply its endorsement, recommendation, or favoring by the United States Government or any agency thereof. The views and opinions of authors expressed herein do not necessarily state or reflect those of the United States Government or any agency thereof. 


\section{DISCLAIMER}

Portions of this document may be illegible in electronic image products. Images are produced from the best available original document. 


\section{Printed in IISA. Prire $\$ 1.50$}

Office of Technical Services

Department of Commerce

Washington 25, D.C.

\section{LEGAL NOTICE}

This report was prepared as an account of Government sponsored work. Neither the United States, nor the Commission, nor any person acting on behalf of the Commission:

A. Makes any warranty or representation, expressed or implied, with respect to the accuracy, completeness, or usefulness of the information contained in this report, or that the use of any information, apparatus, method, or process disclosed in this report may not infringe privately owned rights; or

B. Assumes any liabilities with respect to the use of, or for damages resulting from the use of any information, apparatus, method, or process disclosed in this report.

As used in the above, "person acting on behalf of the Commission" includes any employee or contractor of the Commission, or employee of such contractor, to the extent that such employee or contractor of the Commission, or employee of such contractor prepares, disseminates, or provides access to, any information pursuant to his employment or contract with the Commission, or his employment with such contractor. 


\author{
Contract No. W-7405-eng-26
}

HEALTH PHYSICS DIVISION

TTE COSINE-CUBED NEUTRON SPECTROMETER

J. H. Thorngate

G. S. Hurst

F. J. Davis

P. W. Reinhardt

Submitted as a thesis to the Faculty of the Graduate School of Vanderbilt University in partial fulfillment of the requirements for the degree of Master of Science in Physics.

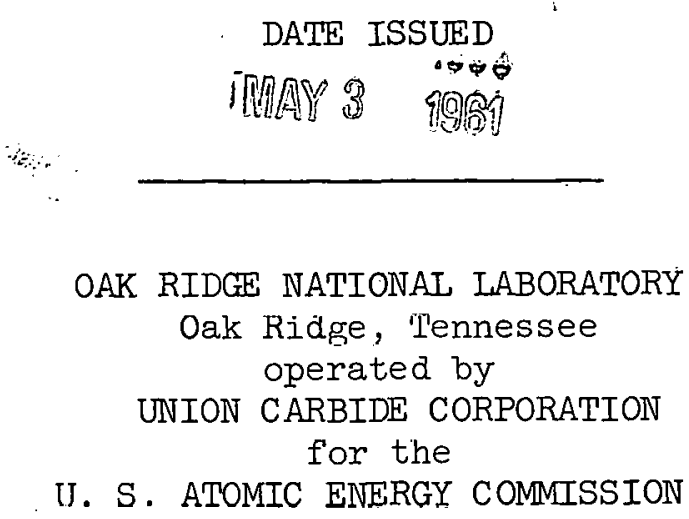




\section{ACKNOWLEDGMENTS}

The authors would like to express their appreciation and thanks to J. A. Harter, H. F. Holzer, and R. M. Simmons for their help with this research. 
TABLE OF CONTENTS

Page

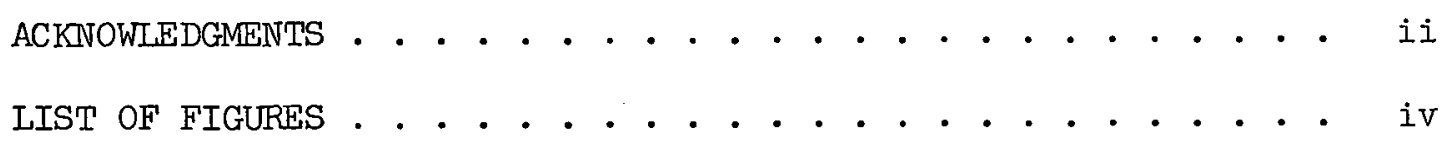

I. INTRODUCTION . . . . . . . . . . . . . . I

II. THEORY . . . . . . . . . . . . . . . . 7

III. APPARATUS . . . . . . . . . . . . . . . 15

The Basic Cosine-Cubed Neutron Spectrometer

The Cosine-Cubed Neutron Spectrometer with

Coincidence

IV. PRELIMINARY STUDLES OF THF CRYSTAL . . . . . . . . 31

Resolution

Pulse Height Comparisons

V. SPECTROMETER PERFORMANCE ............... 42

Response of the Basic Spectrometer Using Argon

Response of the Coincidence Spectrometer Using Argon

Response of the Coincidence Spectrometer Using Xenon

VI. CONCLUSIONS . . . . . . . . . . . . . . 50

BIBLIOGRAPHY . . . . . . . . . . . . . . . . . 53 


\section{- LIST OF FIGURES}

Figure

Page

1. Basic Cosine Cubed Spectrometer . . . . . . . . 16

2. Basic Spectrometer Electronics . . . . . . . 20

3. Gas System .................. . 21

4. Cosine Cubed Coincidence Spectrometer....... . 24

5. Coincidence Electronics. . . . . . . . . . 26

6. Diagrammatic Representation of Crystal Sections . . . 32

7. Diagram of Collimated Alpha Source in Chamber of Spectrometer . . . . . . . . . . . 33

8. Alpha Studies Electronics . . . . . . . . . 35

9. Section $1 \mathrm{Pu}^{239}$ Alpha Peak . . . . . . . . . 36

10. PoBe Data with Argon in the Chamber . . . . . . . 46

11. PoBe Data with Xenon in the Chamber. . . . . . . 48

12. PoB Data with Xenon in the Chamber......... 49 
ABSTRACT

In an attempt to increase the efficiency, a proton recoil neutron spectrometer has been built in which the proton detection crystal is in the shape of the surface formed by the rotation of the $\cos ^{3} \theta$ curve about the $\theta=0$ axis where $\theta$ is the angle between the direction of travel of the incident neutron and the direction of travel of the recoil proton. Such a construction makes the detector crystal conform to the range envelope of the protons recoiling from a neutron beam of sufficiently high energy into a gas in which the proton range is proportional to the $3 / 2$ power of the proton energy. . Sixteen pieces of thallium activated cesium iodide were assembled as a mosaic arranged in the $\cos ^{3} \theta$ shape so that the maximum $\theta$ was $30^{\circ}$. Calculations show that $25 \%$ of the protons recoil within $30^{\circ}$. The PoBe and PoB spectra were measured with the instrument using xenon in the chamber. The resolution of the spectra obtained was low due to nonuniform pulse height response of the CsI crystal sections and excessive gamma-ray response even though an anthracene proton radiator was used in a coincidence scheme designed to minimize gamma-ray background. The instrument did not exhibit the added efficiency which was being sought in the design. The necessity of single channel operation further limits its usefulness. 


\section{INTRODUCTION}

The two major problems in neutron spectroscopy are the detection of the neutron and measurements of its energy. Many different neutron spectrometers have been designed, most of which may be placed into one of four general groups: 1) velocity selection neutron spectrometers; 2) scintillation neutron spectrometers; 3) nuclear reaction neutron spectrometers, and 4) proton recoil neutron spectrometers. Because neutrons cause essentially no direct ionization, they must be detected by observing some ionizing particle resulting from a reaction with the neutron. With the exception of the velocity selectors, neutron spectrometers dif'fer mainly in the reaction used to produce a charged particle. Proton recoil neutron spectrometers utilize the elastic collision between the incident neutron and a proton in some hydrogenous material. The resulting recoil proton is heavily ionizing and easy to detect.

A simple proton recoil neutron spectrometer consists of a gaseous, liquid, or solid proton radiator and a counter to detect the recoil proton and measure its energy. The energy of the recoil proton is related to the energy of the incident neutron by the square of the cosine of the angle between the direction of travel of the incident neutron and the direction of travel of the recoil proton. To obtain an 
unambiguous relationship between proton energy and neutron energy the incident neutron beam has to be collimated, and the counter must be designed to measure the protons given off in some known direction. Because the energy relationship depends upon the cosine of the angle, it is generally best to study only those protons coming from the radiator with the same direction of travel as the incident neutrons for they have the same energy as the incident neutron.

Most sources of neutrons have large amounts of associated gammarays so that the simple spectrometer described would have a higher gamma-ray count than proton count due to the relatively small cross section for the proton recoil reaction. The most successful means of overcoming the difficulties of a high gamma-ray background is by the addition of coincidence techniques to the simple spectrometer.

The first proton recoil neutron spectrometers developed were used in. studies made independently by Watt ${ }^{l}$ and $\mathrm{Hill}^{2}$ of the neutron spectrum from the fission of $\mathrm{U}^{235}$. They obtained their final results by differentiating the curve of coincidence count versus absorber thickness produced when absorbers of varying thickness were placed between the

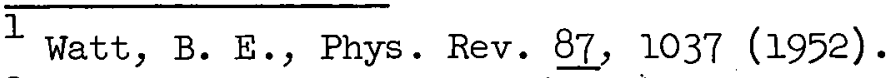

2 Hill, D. L., Phys. Rev. 87, 1034 (1952).
} 
proton radiator and a bank of proportional counters operating in coincidence. Cochran and Henry ${ }^{3}$ at ORNL built a more advanced unit in which absorbers of varying thickness were placed between the radiator and three proportional counters operating in coincidence. To insure maximum efficiency they also used radiators of varying thickness. The bias of the counters was set to count only the protons whose range ended in the final counter; thus the spectrometer responded to a limited energy region for each radiator-absorber combination. Cochran anō Henry placed the radiator-absorber combinations on a wheel so that they could be changed easily when a wide range of energies was to be studied. Absorber-type spectrometers have low efficiency because they are either integral bias or single channel units. In addition, it is possible for them to have large errors due to large angle multiple scattering within the absorber.

The next proton recoil spectrometers developed determined the energy of the recoil proton from the specific ionization or from the range of the proton, which allowed multichannel operation within a limited range of energies. Reid 4 constructed a spectrometer which measured the energy loss of a proton as it traversed a triple coincidence counter. To increase the energy loss at high energies an absorber was placed between the radiator and the counter. This

3 Cochran, R. G., and Henry, K. M., Rev. Sc1. Instr. 26, 757 (1955). 4 Reid, C. C., Proc. Phys. Soc. (London) A-67, 466 (1954). 
limited the range of the unit by introducing a low-energy cut-off.

Such a limitation was not too serious as the maximum efficiency of the radiator covered a limited range also. Holt and Litherland ${ }^{5}$ at Liverpool built a spectrometer which measured the range of the recoil proton in argon by determining the time required for the proton to cross the chamber to a collector plate. To scan the energy region of 5 to 25 Mev, pressures up to 400 psi were required. Although this instrument was quite slow, due to the long electron transit time, it did have good resolution.

Most multichannel spectrometers utilize a coincidence circuit which gates an analyzer to accept, the pulse from a detector which is designed to absorb the entire energy of the recoil proton. Except for minor energy losses in the coincidence counters the amplitude of this pulse is directly related to the energy of the proton. The first spectrometers of this type used gas counters. Nereson and Darden ${ }^{6}$ used a double coincidence unit in which a thin first counter was set to operate the gate so that the analyzer would see the puise produced in a- long Frisch grid chamber. - A third counter was set in anticoincidence after the Frisch chamber so that only protons whose range ended in the long counter would be measured. The difficulties caused by trying to

\footnotetext{
5 Holt, J. R., and Litherland, A. E., Rev. Sci. Instr. 25, 298 (1954). 6

Nereson, N., and Darden, S., Phys. Rev. 89, 775 (1953).
} 
construct two similar counters of considerably different size was overcome by the introduction of a solid scintillator' as the final detector. This was done simultaneously, around 1954, in three different laboratories $^{7-9}$.

A different type of proton recoil spectrometer is one in which one of the counters is the proton radiator. A spectrometer using the gas of the first counter as the radiator was introduced by SchmidtRohr ${ }^{10}$ who used hydrogen, and later developed by Perlow ${ }^{11}$ who used methane. Mozely and Shoemaker ${ }^{12}$ introduced a counter which utilized one anthracene crystal as the radiator and another anthracene crystal as the final counter. By using similar radiator and detector crystals it was fairly easy to obtain the energy of the proton by summing the . pulses electronically. Calvert, Jaffe and Maslin ${ }^{13}$ built a similar unit which utilized an anthracene radiator and a NaI (TI) detector crystal. The pulse energies had to be added by hand, but the unit benefited by the greater light output and better resolution of the NaI

\footnotetext{
7 Ribe, F. L., and Seagrave, J. D., Phys. Rev. 94, 934 (1954).

8 Johnson, C. H., and Trail, C. C., Rev. Sci. Instr. 27, 468 (1956).

9 Risser, J. R., Price, J., and Class, C. M., Phys. Rev. 98, 1183-A (1955).

10 Schmidt-Rohr, U., Z. Naturforsch. 8a, 470 (1953).

11 Perlow, G. J., Rev. Sci. Instr. 27, 460 (1956).

12 Mozely, R. F., and Shoemaker, F. C., Rev. Sci. Instr. 23, 569 (1952).

13 Calvert, J. M., Jaffe, A. A., and Maslin, E. E., Proc. Phys. Soc. (London) A-68, 1017 (1955).
} 
crystal. These thick radiator spectrometers have higher efficiency than thin radiator spectrometers although how much higher cannot be exactly measured due to the effect of the multiple scattering of the proton before it leaves the radiator.

The major disadvantage of all the spectrometers described is the necessity of utilizing the proton recoils in only a small region around some particular angle in order to correlate the energy of the protons with the energy of the incident neutrons. This reduces the overall efficiency of the spectrometer by limiting the number of proton recoils which can be studied.

The aim of the present study has been to design and construct a proton recoil fast neutron spectrometer to overcome this limitation. The cosine-cubed fast neutron spectrometer uses a thin crystal detector built to utilize the recoil protons which come from the radiator in a large solid angle. The spectrometer measures, the energy of the protons from their range which is determined by varying the gas pressure within the chamber of the spectrometer.

Studies have also been made using a.thick anthracene scintillator as the proton radiator in which the pulse caused by a recoil proton in the radiator is used to provide the gate signal to a coincidence circuit designed to overcome gamma-ray background difficulties. 


\section{THEORY}

The uniqueness of the cosine-cubed neutron spectrometer lies in the shape of the crystal used to detect the recoil protons. This crystal is in the shape of the surface formed by the revolution of the

curve $y=\cos ^{3} \theta$ about the $\theta=0^{\circ}$ axis. This configuration is based upon the range-energy relationship of protons in a gas and upon the mechanics of the proton recoi]. neutron reaction.

The elastic collision between a neutron and a proton is mechanically similar to the collision of two billiard balls and may be treated for non-relativistic neutrons with simple Newtonian mechanics. The reaction may be shown diagramatically in the laboratory frame of reference as:

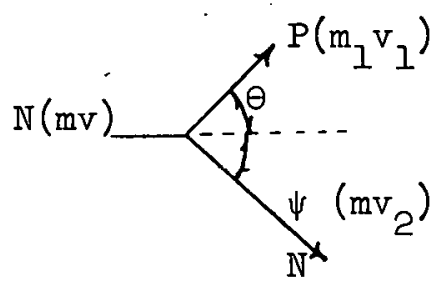

where $\mathbb{N}$ is the neutron, and $P$ is the proton. The momentum of the neutron prior to the collision is (mv) while its momentum after the collision is shown as $\left(\mathrm{mv}_{2}\right)$. The momentum of the proton before the reaction, when it is assumed at rest, is zero. After the collision, the proton has gained the momentum $\left(m_{1} v_{l}\right)$. The angle $\theta$ is the angle between the direction of travel of the incident neutron and the direction of travel of the recoil proton. Similarily, $\psi$ is the angle between 
the directions of travel of the neutron before and after the collision. For an elastic collision, conservation of kinetic energy and conservation of momentum can be expressed by the equations:

$$
\begin{aligned}
\mathrm{mv} & =\mathrm{m}_{1} \mathrm{v}_{1} \cos \theta+\mathrm{mv}_{2} \cos \psi \\
0 & =\mathrm{m}_{1} \mathrm{v}_{1} \sin \theta+\mathrm{mv}_{2} \sin \psi \\
1 / 2 \mathrm{mv}^{2} & =1 / 2 \mathrm{~m}_{1} \mathrm{v}_{1}^{2}+1 / 2 \mathrm{mv}_{2}^{2}
\end{aligned}
$$

From these equations the velocity of the recoil proton with respect to the velocity of the incident neutron is found to be

$$
v_{1}=\frac{2 m \cos \theta}{\left(m+m_{1}\right)} v
$$

From Equation (4), the dependence of the energy of the proton $\left(E_{\theta}\right)$ recoiling at any angle $\theta$ on the energy of the incident neutron $\left(E_{0}\right)$ is:

$$
E_{\theta}=\frac{4 m_{1} m}{\left(m_{1}+m\right)^{2}} \cos ^{2} \theta E_{0} .
$$


If the proton and neutron are assumed to have equal mass, Equation (5) becomes:

$$
\mathrm{E}_{\theta}=\cos ^{2} \theta \mathrm{E}_{0}
$$

From the recoll reaction in the center of mass system, it is possible to derive an expression.for the angular distribution of the recoil protons. Here $\theta$ indicates the same angle as previously, while $\phi$ is the angle by which the incident neutron and recoil proton are deflected in the center of mass system. The number of recoils projected between the angles $\theta$ and $\theta+d \theta$ in the laboratory system by $\mathbb{N}_{0}$ incident neutrons is $d \mathbb{N}$ and the number of scattering protons per unit area is $\eta$. The differential cross section for the reaction per unit solid angle in the center of mass system may be denoted by $\sigma_{c}(\Phi)$. The relation between these quantities is:

$$
d N=2 \pi N N_{0} \eta \sigma_{c}(\phi) \sin \phi\left|\frac{d \phi}{d \theta}\right| d \theta \quad
$$

For elastic, non-relativistic reactions such as those under consideration:

$$
\theta=\frac{\pi-\Phi}{2}
$$


so that

$$
\sin \phi=\sin 2 \theta
$$

For this case Equation (7) becomes:

$$
\mathrm{dN}=4 \pi \mathrm{N}_{\mathrm{O}} \eta \sigma_{\mathrm{c}}(\phi) \sin 2 \theta \mathrm{d} \theta,
$$

and the total number of proton recoils deflected between 0 and $\theta$ degrees is given by the integrated expression:

$$
\mathrm{N}=4 \pi \mathrm{N}_{0} \eta \sigma_{c}(\phi) \sin ^{2} \theta
$$

This equation indicates the advantage of having a detector which would utilize the protons scattered within a large angle to the forward direction.

To maintain energy correlation between incident neutrons and recoil protons the proton detector in the cosine-cubed neutron spectrometer is shaped to fit the range envelope of the recoil protons. When this is done, neutrons of a given energy will produce recoil protons which, for a particular gas pressure within the spectrometer chamber, will just reach the detector regardless of their recoil angle. 
In general, the range of a proton in a gas can be expressed as a function of the proton energy by the relation:

$$
R=\frac{k E^{n}}{P},
$$

in which $R$ is the range of the proton, $k$ is a constant whose value depends upon the gas and the units in which pressure, energy and range are expressed, the value of $\mathrm{n}$ depends upon the gas and upon the energy of the proton, $E$, and $P$ is the pressure of the gas. If one follows the arguments of Hurst, et. al. ${ }^{14}$, an expression for the range of the recoil proton as a function of the energy of the incident neutron may be found by substituting the expression for the recoil proton energy (Equation 6) into Equation (12). Such a substitution results in the equation:

$$
R=\frac{k E_{0}^{n} \cos ^{2 n} \theta}{P}
$$

The exact value of $\mathrm{n}$ may be found by the application of Geiger's Law to the range-energy relationships for protons in gases calculated by Hirschfclder and Mage ${ }^{15}$ whose work is an extension of Bethe's ${ }^{16}$ work on stopping powers.

$\overline{14}$ Hurst, G. S., et al., ORNL-2049, Oak Ridge National Laboratory, Oak Ridge, Tennessee, (1956) p. 54.

15 Hirschfelder, J. 0., and Magee, J. L., Phys. Rev. 73, 207 (1948). 16 Bethe, H., HANDBUCH DER PHYSIK (Springer-Verlag, Berlin, 1933) Volume 24, Part I, page 521. 
In Bethe's semi-empirical method of determing the range, the effective ionization potential for the electrons in the outermost shell is adjusted to fit an experimental value of alpha particle range while the remainder of the constants in the functional equations are determined from theoretical considerations. The resulting form of the range-energy relationships is valid for proton energies greater than $0.1 \mathrm{Mev}$.

For protons, the equation:

$$
\frac{\mathrm{dP}}{\mathrm{dR}}=2 m e^{4} \quad \frac{\mathrm{M}}{\mathrm{m}} \mathrm{N} \quad \frac{\mathrm{B}}{\mathrm{E}}
$$

represents the change in energy, $\mathrm{E}(\mathrm{Mev})$, with residual range, $\mathrm{R}(\mathrm{cm})$. Here $\mathrm{M} / \mathrm{m}$ is the ratio of the mass of the proton to the mass of the electron, $e$ is the electronic charge, and $N$ is the number of atoms per cubic centimeter. The dimensionless quantity B is the stopping number which is closely related to the atomic stopping cross section $\sigma$ (electron volts $\mathrm{cm}^{2}$ ):

$$
\sigma \times 10^{15}=0.3292 \frac{\mathrm{B}}{\mathrm{E}}
$$

in which $\sigma$ is defined so that

$$
\frac{\mathrm{dE}}{\mathrm{dR}}=\mathrm{N} \sigma \times 10^{-6} .
$$


The range of a proton in a substance may be calculated by the numerical integration of

$$
\int_{0}^{E} \frac{d R}{d E} d E
$$

where

$$
\frac{\mathrm{dR}}{\mathrm{dE}}=\frac{39.25}{\sigma \times 10^{15}} .
$$

At low energies the range is roughly proportional to $E^{1 / 2}$ but the exponent increases with energy until at high proton energies:

$$
R=\frac{k E^{3 / 2}}{P} \text {. }
$$

That is, n approximates 3/2 for proton energies greater than $500 \mathrm{Kev}$. When this value of $\mathrm{n}$ is used in Equation (13) the relationship between recoil proton range and incident neutron energy becomes:

$$
R=\frac{\mathrm{kE}_{\mathrm{o}}^{3 / 2} \cos ^{3} \theta}{P}
$$

Therefore, for a given neutron energy $E_{0}$ and with a given gas pressure $P$, the range envelope of the recoil protons is the surface formed by rotating a $\cos ^{3} \theta$ curve about the $\theta=0$ axis, provided the energy of the incident neutron is sufficiently high so that $n=3 / 2$ for the recoil protons. 
The range-energy relationship derived by Hirschfelder and Magee ${ }^{17}$ is a function of the atomic stopping cross section $\sigma$, which is dependent upon the atomic number of the absorbing material, so that $\mathrm{n}$ approaches the value $3 / 2$ at a lower energy for an absorbing gas with a high $\mathrm{z}$. The gas used, xenon, has a relatively high $\mathrm{Z}$, so the value of $\mathrm{n}$ is very close to $3 / 2$ for proton energies as low as $500 \mathrm{Kev}$. The $\cos ^{3} \theta$ shaped crystal of the instrument had a maximum $\theta$ of $30^{\circ}$ so that the incident neutrons had to have an energy of approximately $677 \mathrm{Kev}$ to insure that all the recoil protons would have sufficient energy to satisfy the requirement that $n=3 / 2$.

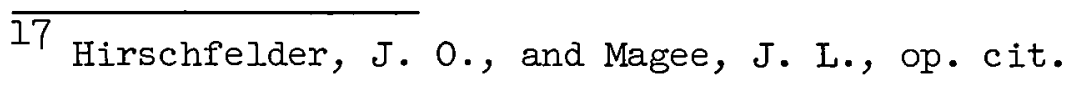




\section{APPARATUS}

\section{A. The Basic Cosine-Cubed Neutron Spectrometer}

Figure (1) is a drawing of the cosine-cubed neutron spectrometer as it was originally designed. The items are numbered to aid in the explanation of the construction.

Basically the spectrometer consists of a mild steel cylinder with provisions for mounting the proton radiator and the cos ${ }^{3}$ crystal. The device was designed to utilize the protons recoiling at angles up to $\theta=30^{\circ}$ for which the resulting crystal was close to the maximum size that could be used with a single photo-multiplier tube. An auxillary, thin-walled, mild steel tube is added to enclose and act as a magnetic shield for the photo-multiplier tube.

The tube (1) entering the base of the chamber is the gas inlet. A removable plug (2) was designed to hold the proton radiator and was provided with means of holding a collimator (5) for the protons. Three lengths of collimators, as indicated by (5), (6), and (7), were constructed to provide varying amounts of collimation. The chamber (4) is made of mild steel and has an outside diameter of roughly five and one-quarter inches and an inside diameter of four inches.

The scintillation crystal (8) is made of sixteen pieces of $1 / 16 "$ thick cesium iodide pieced together in the shape of the surface of a 


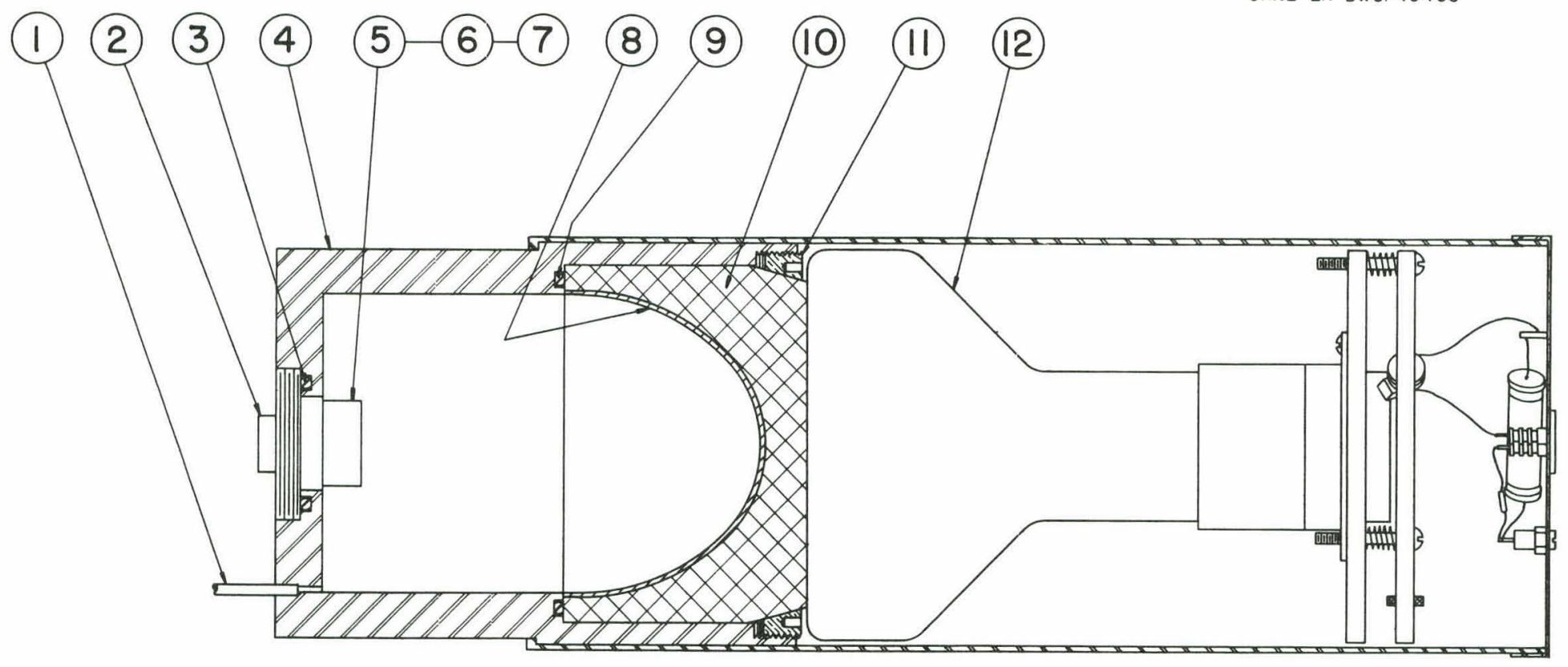

FIG. I BASIC $\operatorname{Cos}^{3}$ SPECTROMETER 
$\cos ^{3}$ curve of revolution. The crystal is mounted on a lucite light pipe (10) which is held in the chamber by a retainer ring (11). "O" ring seals (3 and 9) are used to provide a pressure-vacuum seal for the chamber.

The photo-multiplier tube (12) is a five-inch Dumont 6364 which is held against the lucite light pipe by a spring-loaded socket assembly. The socket assembly fastens to the mild steel tube with set screws. The only electronics contained within the unit is the divider network for the photo-multiplier tube. The high voltage and signal terminals are type BNC-IPC No. 27,000, and are fastened to the end cover which is held in place by a friction fit. A light-tight seal is assured by application of opaque tape around the junction of the mild steel tube and the chamber and over the end cover joint'.

Scintillations from the crystal are transmitted through the lucite light pipe to the photo-multiplier tube. An optical coupling is maintained between the light pipe and the photo-tube by using a clear silicon fluid Dow-Corning 200, at the interface. Fluid with 500,000 centistoke viscosity was used in the exploratory stages of the work and $1,000,000$ centistoke fluid was used in obtaining spectral data. The cosine-cubed neutron spectrometer measures neutron energy by measuring the range of the recoil protons produced by elastic collisions of the neutrons with the hydrogen atom nuclei of a hydrogenous radiator. 
The spectrometer is designed so that the actual range used remains constant while the amount of absorber between the proton radiator and the detector crystal is changed by changing the pressure of the gas in the chamber. If the proton just reaches the crystal and produces only a small pulse, the distance from radiator to crystal approximates the range for protons of that energy. Protons of lower energy will lack the necessary energy to penetrate the gas and will not reach the crystal. A proton of higher energy will produce a larger pulse than that caused by the proton which just reaches the crystal, so that the pulse can be rejected electronically by a single-channel differential pulse height analyzer set so that only the smallest pulses detectable above noise are registered. In actual practice a proton cannot be exactly at the end of its range when it strikes the crystal or it would not produce a pulse in the crystal large enough to overcome the noise of the electronics. Some correction to the apparent energy must be in any spectrum to compensate for this.

The electronic equipment used was straight forward and all of the items used were readily available. The Dumont 6364, five-inch photomultiplier tube was set up with a divider network whose total resistance was near 5 megohms. The voltage applied across the divider was approximately 1,310 volts which was supplied by an ORNL super-stable high voltage power supply. The output from the photo-multiplier is fed into a standard AIA pre-amplifier which in turn feeds a standard Al 
linear amplifier. The output from the linear amplifier is fed to a differential pulse height analyzer. The signal from the analyzer was then fed into a standard binary scaler. This set-up is shown diagramatically as a block diagram in Figure (2).

The gas system is quite simple and consists of a manifold with the necessary connections for the spectrometer chamber, the differential pressure gauge and the vacuum pump. Connections were provided so that two gas cylinders could be used simultaneously. A valve was installed so that the device could be vented to the atmosphere when desired. A diagram of the system is presented as Figure (3).

The differential pressure gauge has a connection to the case or outside chamber and another to a smaller, sensitive volume. The gauge reads in $\mathrm{cm}$ of $\mathrm{Hg}$ with the case pressure as the reference.

Although three different gases, nitrogen, argon, xenon, were used in the chamber during the course of the experiment, only two connections were provided for gas cylinders because no more than two gases were used at any one time.

When the spectrometer was to be used, the cylinder valves and the valve to the atmosphere were closed and the regulators and valves to the cylinders, the chamber valve, both gauge valves and the valve to the vacuum pump were opened. Then the system was pumped down over night. To put the spectrometer in use, the valves to the gas cylinders, the vacuum pump and the case side of the gauge were closed. Then the proper 
UNCLASSIFIED

ORNL-LR-DWG. 49492

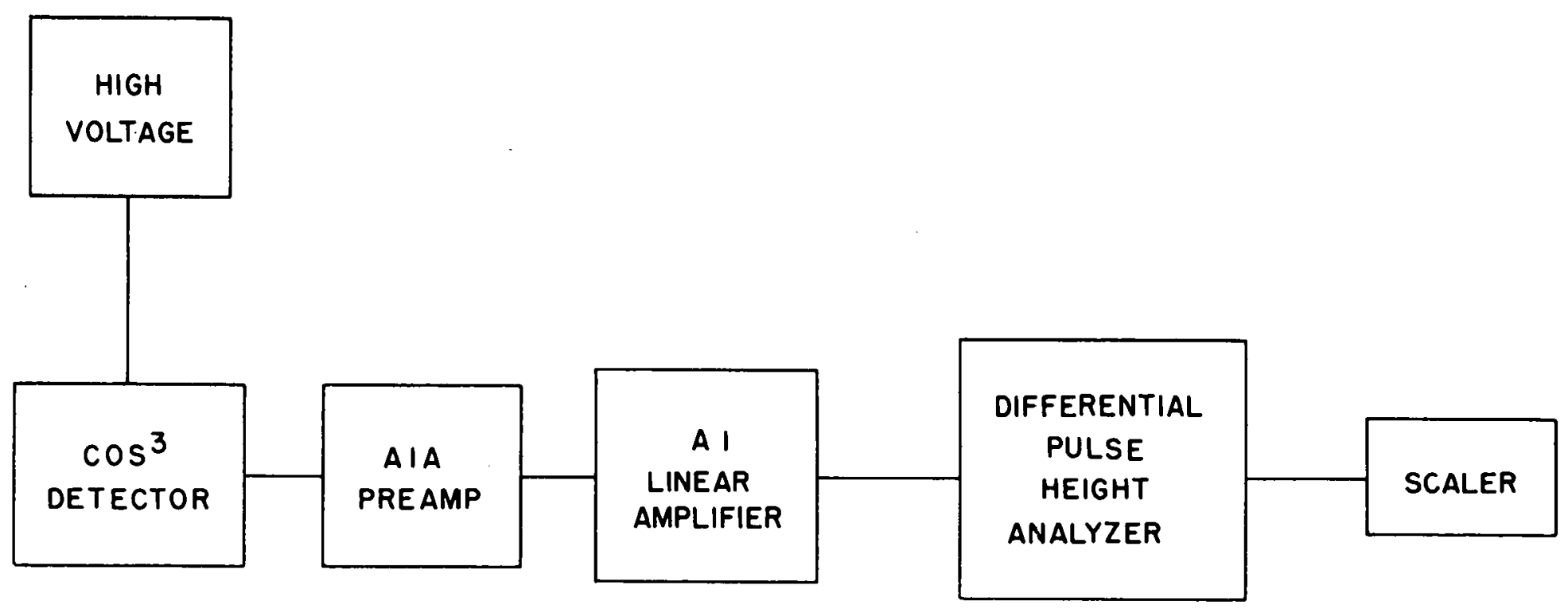

FIG. 2 BASIC SPECTROMETER ELECTRONICS 
UNCLASSIFIED

ORNL -LR-DWG. 49487

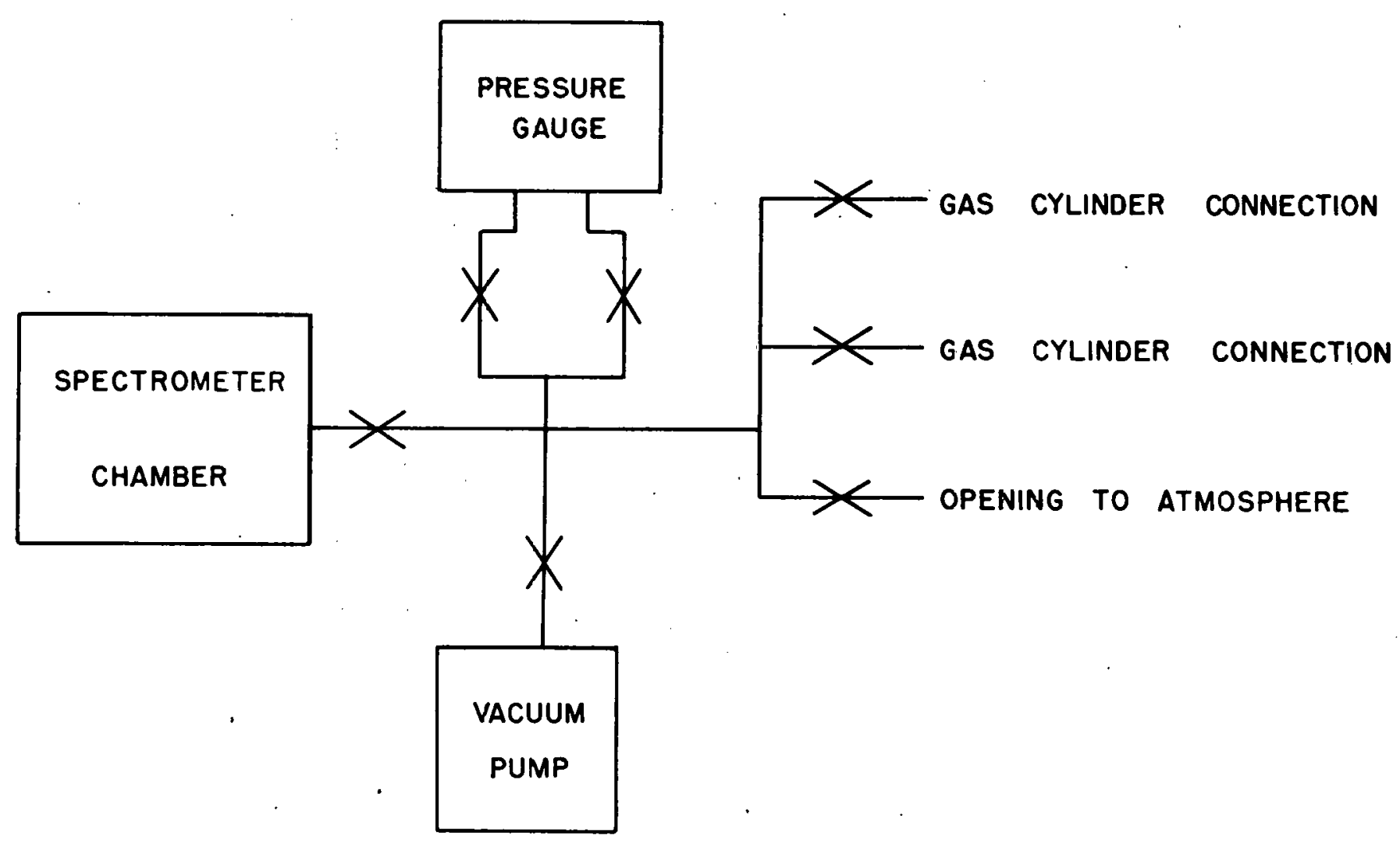

FIG. 3

GAS SYSTEM 
gas cylinder was opened, and the amount of gas necessary to produce the desired pressure in the chamber was put into the system.

In the preliminary studies, when nitrogen or argon was used as the gas in the chamber, no attempt was made to save the gas, and when the study was completed the gas was vented to the atmosphere. Recovery was made of the design gas, xenon, due to the difficulty of obtaining pure xenon. A simple means of recovering the gas was used which consisted of placing the small xenon cylinder in a bath of liquid nitrogen when recovery was desired. The temperature of the liquid nitrogen was. low enough to condense the xenon remaining in the cylinder, which reduced the pressure in the cylinder so that the remainder of the gas in the system was drawn back into the cylinder. This system could not result in perfect recovery, but if a long enough condensing period was used only a small portion of the xenon was left in the system. This method worked very well in actual practice.

It was found by alternately using lead or paraffin shielding that the simple spectrometer that has been described here did not possess sufficient neutron-to-gamma ray discrimination so that coincidence techniques were necessary to reduce the gamma-ray background before neutron spectra could_be observed. 
B. The Cosine-Cubed Neutron Spectrometer with Coincidence Added

The only change which had to be made on the basic cosine-cubed neutron spectrometer to use coincidence techniques involved replacing the plug designed to hold the proton radiator and collimator with a plug designed to hold a photo-multiplier tube and a different proton radiator. Figure (4) shows the design of the end plug used for coincidence counting. Two new end plugs were fabricated--one to accomodate a $3 / 4 "$ tube, the other designed for a 1-1/4" tube.

An anthracene scintillation crystal was used as the proton radiator with this arrangement so that the recoil proton would produce a pulse as it left the radiator. The electronic equipment used with the spectrometer wore then revised to require a coincidence between the pulse in the anthracene crystal and the cesium iodide crystal before a count would be registered. The proton could satisfy this condition with higher efficiency than a gamma ray, which would not generally cause a scintillation in both crystals.

An anthracene crystal, $1 / 8 "$ thick by $1 "$ in diameter, was mounted to the surface of a Dumont 6467, 1-1/4" photo-multiplier tube with silicone stop-cock grease. The grease was stiff enough to hold the crystal in place during handling and as the spectrometer was used in an upright position no difficulties were encountered due to the anthracene crystal slipping off the photo-multiplier tube. The photo-multiplier tube was wrapped in opaque tape to prevent unwanted light from striking 
UNCLASSIFIED

ORNL LR DWG. 4949

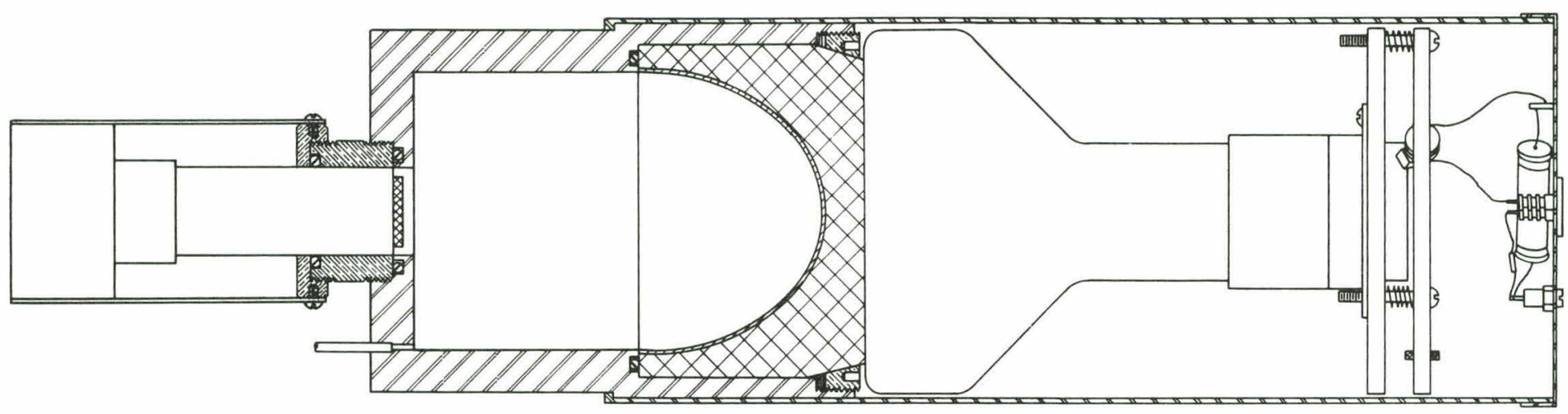

FIG. $4 \quad \operatorname{Cos}^{3}$ COINCIDENCE SPECTROMETER 
the cathode. The rather large diameter of the proton radiator would, of course, decrease the resolution of the spectrometer. The $3 / 4$ " photomultiplier tube used with a $1 / 2^{\prime \prime}$ diameter crystal was planned to improve the situation.

A brace was designed which fastened the photo-tube holder to the photo-tube socket to prevent the photo-tube from being blown out of the holder when the gas pressure in the chamber was increased above atmospheric pressure.

There are several factors which must be taken into account when the scintillator crystal is to be used as the proton radiator. The primary problem is that of placing the radiating surface at the apex of the consine-cubed curve accurately. Any inaccuracy in this setting will cause a decrease in the resolution of the spectrometer. For practical use a positioning device is necessary. In these studies it was felt that in comparison with other possible errors, the resolution errors due to the inexact placing of the proton radiator would not contribute significantly to the loss in overall resolution.

While the mechanical changes necessary in the cosine-cubed coincidence spectrometer were quite simple, the changes made necessary a considerably more complicated electronic system. Figure (5) is a block dlagram of the electronic system used. 
UNCLASSIFIED

ORNL-LR-DWG. 49491

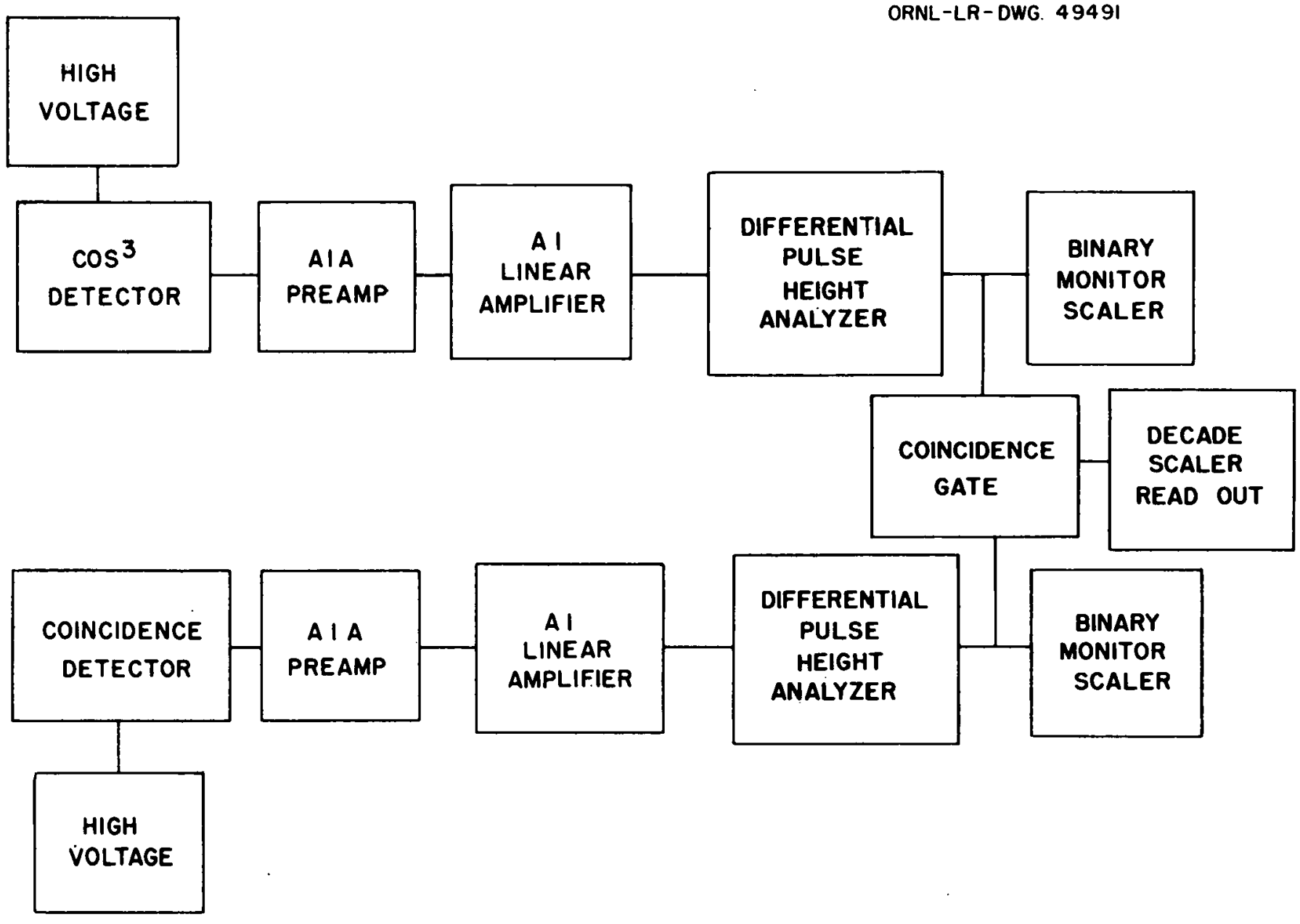

FIG. 5 COINCIDENCE ELECTRONICS 
The 1-1/4" photo-multiplier tube had a 5 Megohm divider network similar to that used with the '5" photo-tube. The 1310 volt supply for each tube was provided from separate ORNL super stable high voltage power supplies.

The output from the small photo-multiplier tube fed a standard AlA pre-amplifier which in turn fed a standard Al linear amplifier. As with the circuit used for the larger photo-multiplier tube, the discriminator in the amplifier was not used; instead, the amplifier output was f'ed into a single channel difterential pulse height analyzer. The outputs from the single channel analyzers fed separate standard scale of 64 binary scalers used for monitoring purposes.

Normally, in a recoil proton fast neutron spectrometer, the thickness of the proton radiator is of great importance to the efficiency of the spectrometer. A thin radiator will not have many neutron-proton collisions within it, but any recoil protons which are produced will lose only a small amount of energy escaping from the radiator. Conversely, a thick radiator will produce more recoil protons but the energy resolution of the spectrometer will be poorer due to the energy lost by the protons as they leave the radiator. In this spectrometer, a thick anthracene crystal was used as the proton radiator. However, the single channel analyzer for the anthracene crystal was set so that only small pulses just above noise would be seen. This guaranteed that the coincidence gate was open only when a proton lost a small amount of 
energy in leaving the anthracene crystal and produced a small scintillation. Therefore, any proton that was produced near the back of the crystal or that went through the crystal with an angular path was rejected electronically. A correction for the amount of energy lost by the proton in leaving the anthracene crystal-proton radiator could be easily made because any proton, regardless of its initial energy, had to lose the same amount of energy in leaving the crystal or it was not counted. The window width, $\triangle E$, used on this analyzer was $0.5 \mathrm{v}$ to insure a small energy loss in the radiator.

The output pulses from the single channel differential pulse height analyzer used with the anthracene crystal were fed into a variable delay line. The delay line was not necessary to correct for the transit time of the protons in the chamber because the chamber was small enough so that the output pulses of the single channel analyzers were longer than the transit time. The delay line was needed to compensate for the difference in decay time for the organic anthracene crystal and the non-organic CsI crystal. Because the discriminators of the single channel analyzers function on the back slope of the amplified pulse, they would fire first for the shorter pulse from the anthracene crystal. Therefore, a slight delay was needed to get the analyzer pulses into coincidence for coincidence pulses.

The output of the single channel analyzer in the cosine-cubed crystal chain and the output of the delay line are fed into a coincidence circuit developed originally by Marshall at the Institute of 
Nuclear Science of the University of Chicago ${ }^{18}$. The ciruit utilizes a 6BN6 gated beam tube as the coincidence gate. The $6 \mathrm{BN} 6$ has two control grids so that when both grids are biased beyond cutoff, plate current will flow only when both grids receive a positive pulse at the same time. The plate impedance is made high to lengthen output pulses to about one micro-second. The circuit should be capable of a resolving time of $3 \times 10^{-10} \mathrm{sec}$, however leakage of single electrons causes a skewed curve when the output voltage is plotted against the delay between the applied input pulses. Marshall stated that the pulse height distribution of the source affected the relation between true coincidence counts and the resolving time. One hundred percent of the pulses can be counted without counting any of the background if the input pulses are $2 \times 10^{-9} \mathrm{sec}$. The pulses encountered with the cosine-cubed neutron spectrometer were $3 \times 10^{-7} \mathrm{sec}$ in duration but were all of uniform size because they came from the discriminators of single channel pulse height analyzers.

The output from the coincidence network was fed into a glow transfer tube, decade scaler-timer. The count of this scaler provided the desired information about the neutron spectrum being studied.

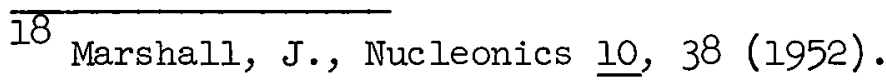


The only unusual instrument used for the coincidence set-up of the cosine-cubed neutron spectrometer was the coincidence circuit itself, which was a very simple circuit. All of the remaining components were readily available items which added to the simplicity of the construction of the spectrometer.

All 110-volt, 60-cycle power used in the power supplies, amplifiers, analyzers, and coincidence circuit was obtained from constant voltage transformers. The power for the scalers was taken directly from the AC line. 


\section{PRELIMINARY STUDIES OF THE CRYSTAL}

\section{A. Resolution}

Each section of the mosaic CsI cosine-cubed crystal was studied separately to determine the resolution of the crystal. The crystal was constructed of sixteen pieces of $1 / 16^{\prime \prime}$ thick CsI which were arranged in the pattern shown in Figure (6), where the projection of the crystal onto the plane of the photo-multiplier tube cathode is shown. For identification purposes the sections were numbered as on the diagram. The single section in the center ring whose edges were completely within the edges of an outer section served as the reference point in the numbering.

A well-collimated $\mathrm{Pu}^{239}$ alpha source was used to study the resolution. The alpha source was in the shape of a small, thin disc $1 / 8$ " in diameter which was mounted at the end of a lucite rod ' $"$ long and $1 / 2$ " in diameter. The rod had a $1 / 8^{\prime \prime}$ hole drilled lengthwise through it which served as the collimator for the alpha particles. The collimator was mounted on another lucite rod long enough to place the collimator as close to the crystal as possible. The long rod was fastened to a special end plug. The collimator was connected to the support rod with a connector which allowed tilting the collimator at an angle with the center line of the chamber so that the alpha source could be pointed at any one of the crystal sections. Figure (7) is a drawing 
UNCLASSIFIED

ORNL-LR-DWG. 49490

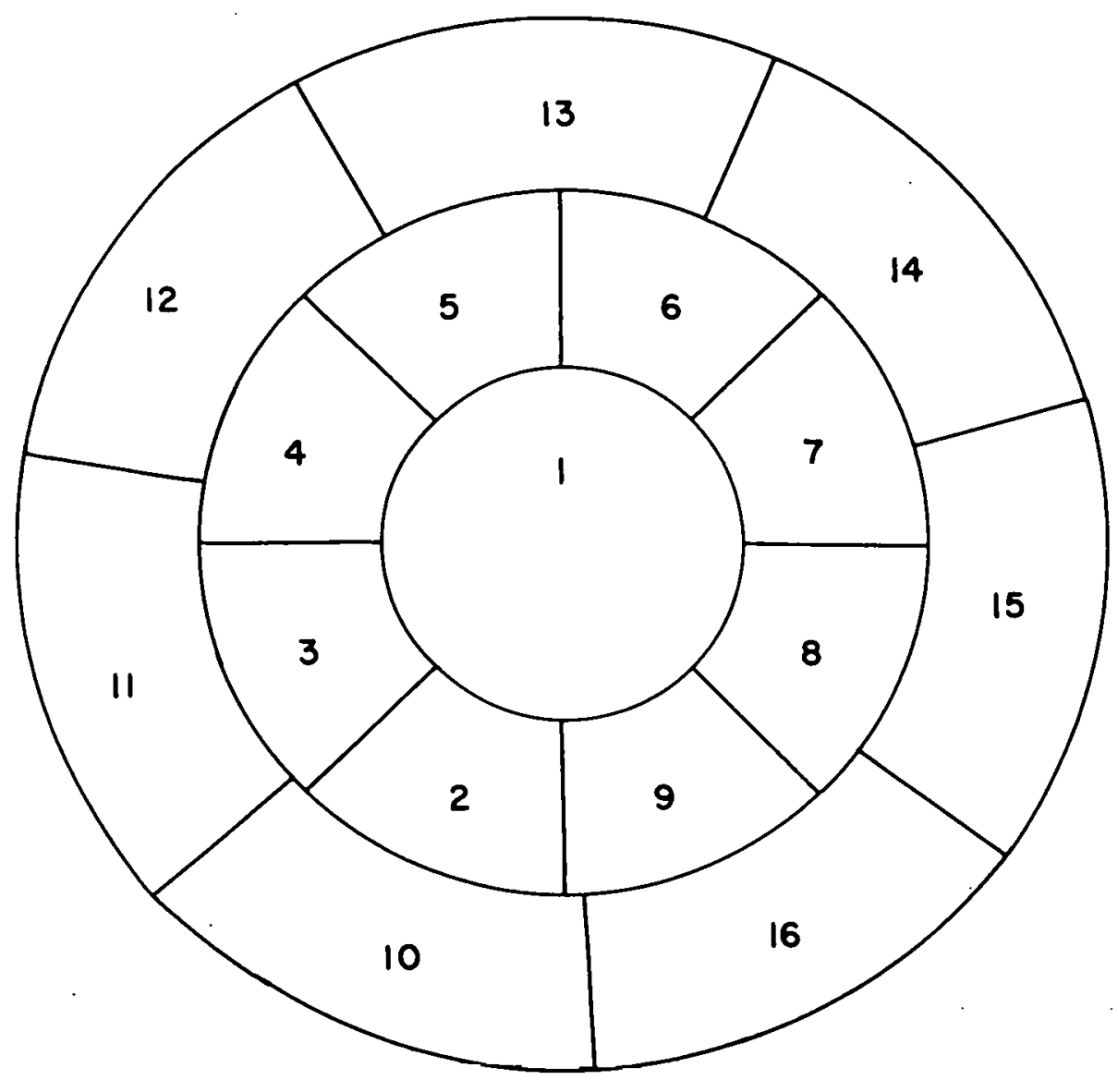

FIG. 6 DIAGRAMMATIC REPRESENTATION OF CRYSTAL SECTION NUMBERS 


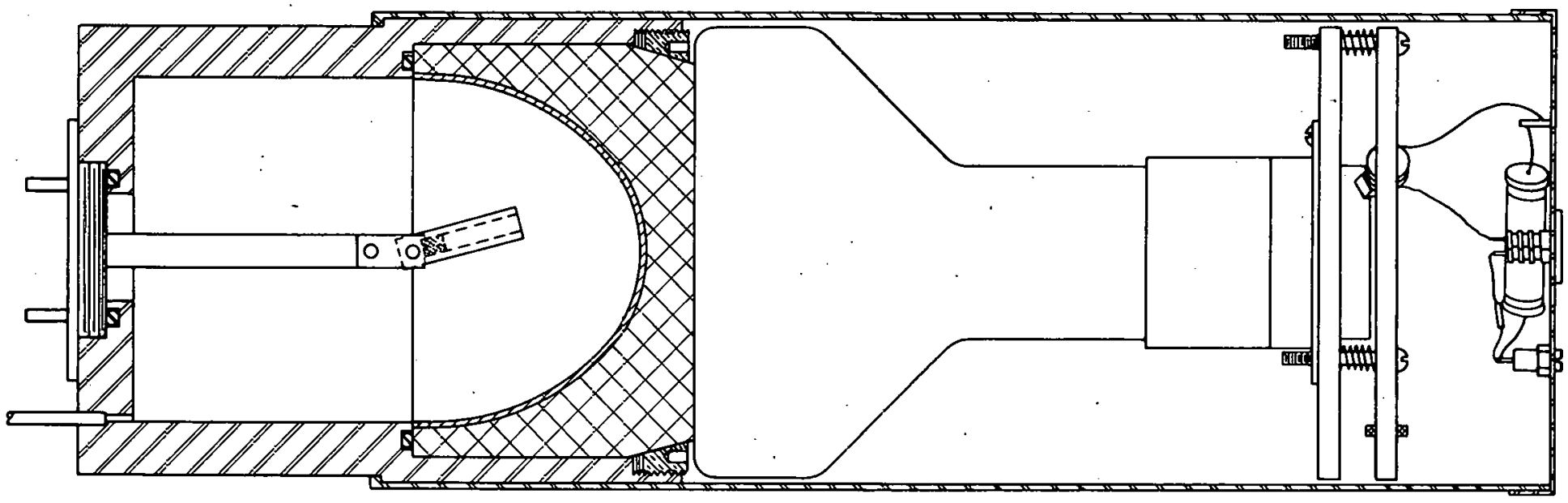

FIG. 7 DIAGRAM OF COLLIMATED ALPHA SOURCE

IN CHAMBER OF SPECTROMETER 
of the spectrometer chamber with the collimated alpha source in place and pointed at the center ring of crystal sections.

The electronic equipment used for these experiments consisted of a simple, single-channel, differential pulse height analyzer. A block diagram of the arrangement used is shown in Figure (8).

The high-voltage supply was operated at a setting of 2050 volts. The power supply had a built-in 5 Megohm series resistor which formed a voltage divider with the 5 Megohm photo-multiplier tube divider network so that only half of the power supply voltage was on the tube. A standard AlA pre-amplifier was used to feed an Al linear amplifier which provided a signal for the differential pulse height analyzer. The output of the analyzer was fed to a standard scale of 64 scaler. The high collimation used resulted in a low counting rate which made ten minute counting periods necessary to obtain one per cent statistics.

Typical data obtained for the energy peak of the collimated alpha source are plotted in Figure (9). As is noted, these are the data for section number 1 of the crystal, the large center section. Similar plots were obtained for each of the sixteen crystal sections.

From the plotted data it is possible to calculate the resolution of the crystal sections for $5 \mathrm{Mev}$ alpha particles. The method used for calculating resolution in this case was to divide the width of the peak at half height by the pulse height at the peak. 
UNCLASSIFIED

ORNL-LR-DWG. 49489

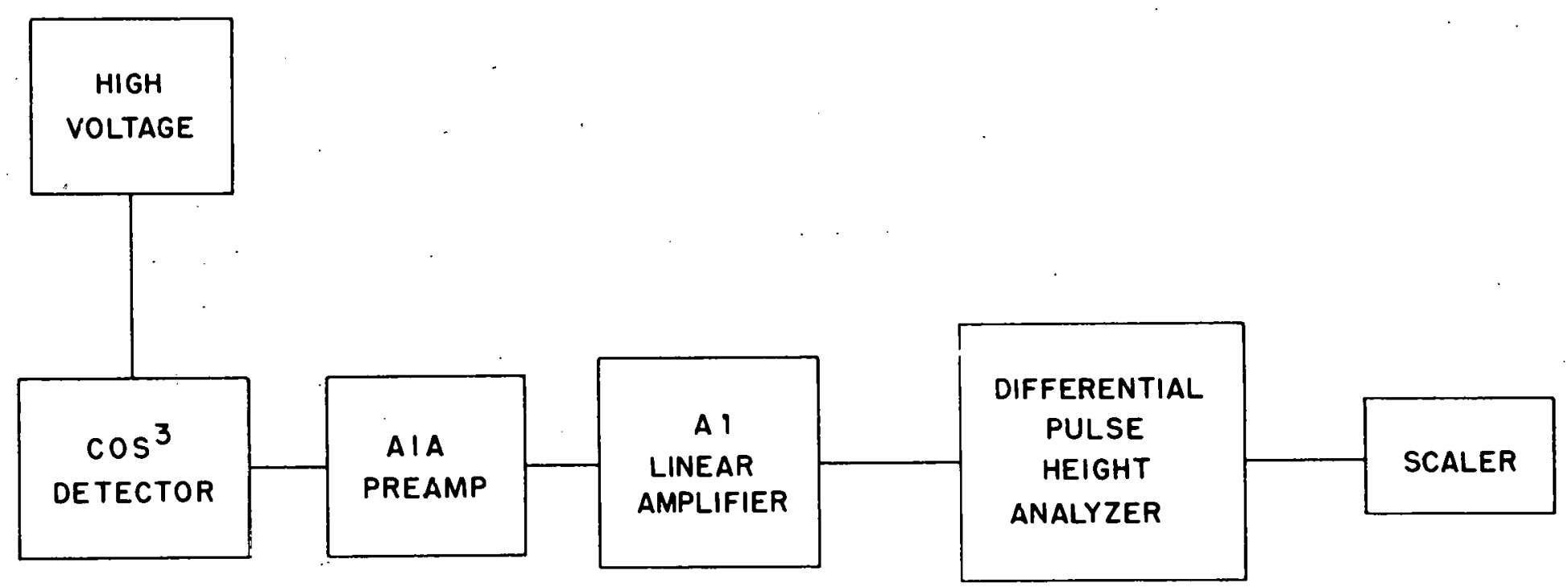

FIG. 8 ALPHA STUDIES ELECTRONICS 
UNCLASSIFIED

ORNL-LR-DWG. 49488

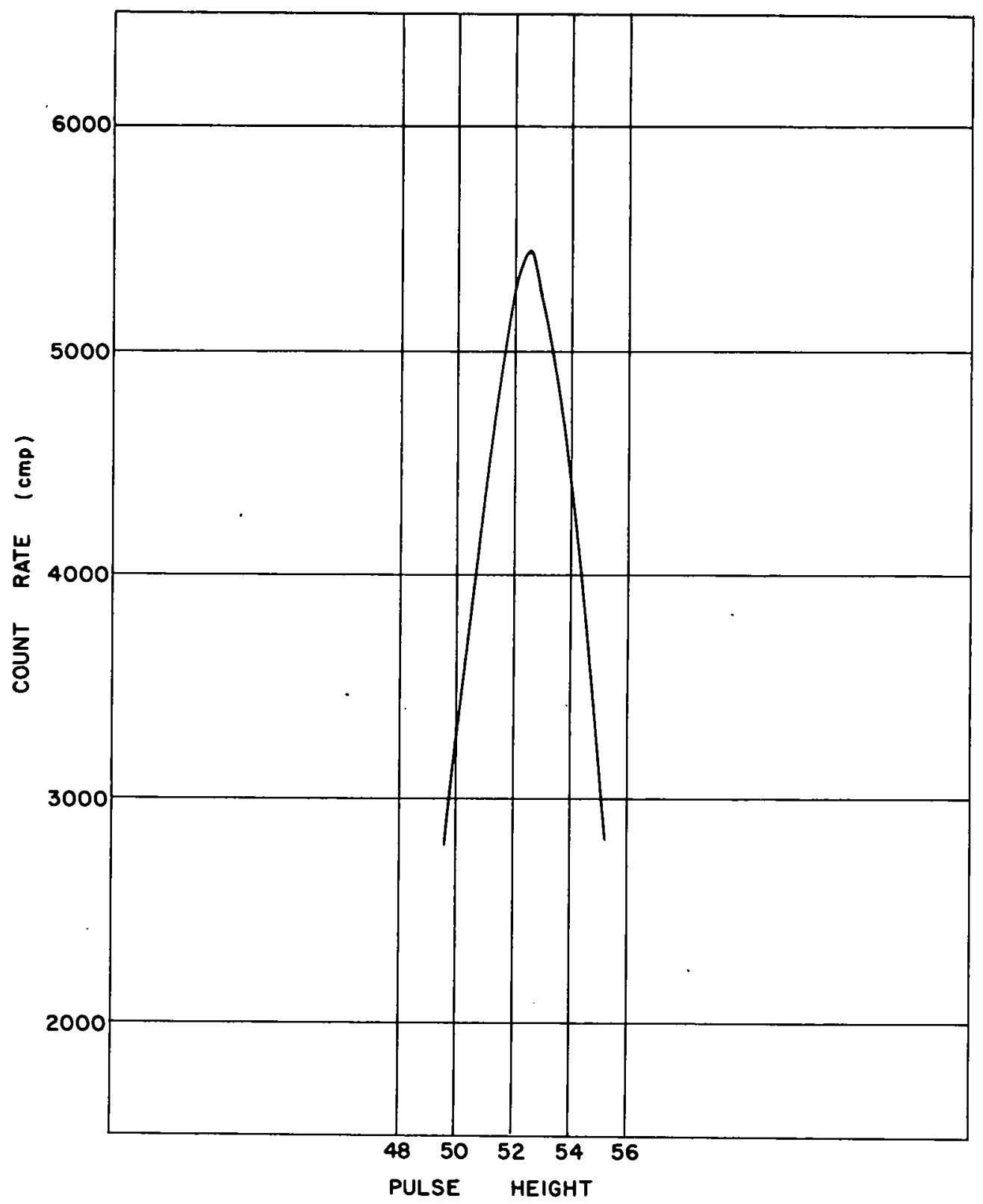

FIG. 9 SECTION I Pu 239 ALPHA PEAK 
A tabulation of the resolutions obtained by this method for each of the sixteen crystal sections is given in Table I. The resolutions obtained by this method for the crystal sections all range around $10 \%$. The principal reason for the finite resolution of a scintillation detector is the statistical spread in the number of photoelectrons produced. in the photocathode by similar incident photons. The spread of the number of electrons produced, coupled with the poorer statistics of photon production for low-energy particles in the scintillator, produced pourer resolution for the crystal sections when the spectrometer was in use than was obtained with alpha particles.

In operation there is a loss of resolution due to scattering of the incoming neutrons and scattering of the protons within the chamber. The protons are more apt to be scattered when high energy neutrons are being studied and higher pressures of xenon are used in the chamber. The resolution of the spectrometer is also impaired by other more fundamental reasons. If the crystals were not exactly the right shape, if the $3 / 2$ relation between range and energy did not hold accurately, and if the separate sections of the crystal produce different pulse heights for i.dentical particles, lower resolution would be expected.

\section{B. Pulse Height Comparisons}

Because the detector crystal is actually sixteen different crystals, any difference in the pulse height response-or the efficiency of the 
TABLE I. Resolution of the Crystal Sections

\begin{tabular}{|c|c|}
\hline Section & $\%$ Resolution \\
\hline 1 & 10.5 \\
\hline 2 & 9.9 \\
\hline 3 & 8.5 \\
\hline 4 & 6.2 \\
\hline 5 & 8.8 \\
\hline 6 & 10.0 \\
\hline 7 & 8.1 \\
\hline 8 & 7.2 \\
\hline 9 & 8.7 \\
\hline 10 & 7.4 \\
\hline 11 & 6.4 \\
\hline 12 & 7.6 \\
\hline 13 & 6.8 \\
\hline 14. & 8.7 \\
\hline 15 & 6.6 \\
\hline 16 & 6.9 \\
\hline
\end{tabular}


individual sections would adversly affect the resolution of the crystal as a whole. The pulse height response of the sections was compared by recording the location of $\mathrm{Pu}^{239}$ alpha peak on the pulse height scale of a differential pulse height analyzer for each section. The efficiency of the crystal sections was measured by placing the same source, under similar conditions of distance and gas pressure, in front of each section of the crystal and comparing the count rates obtained. With the well-collimated alpha source used, it was possible to check each crystal section for pulse height and count rate at the same time.

The data used for this study of the crystal are the same as that used for determining resolution. Table II also shows count rate data obtained at the same time tor each crystal section. Also given in the table is the angular position of each of the crystal sections.

Table II shows that there is some correlation between angular position and crystal response. In other words, one side of the crystal does not respond as well as the other side. Attempts to correct this were made, consisting chiefly of trying to improve the optical contact between the lucite light pipe and the photo-multiplier tube. After redoing the optical contact, a quick examination showed no change in the angular correlation of the differences in the crystal. Therefore, it was felt that the defects must be either in the crystal, in the light pipe, or in the contact between the crystal and the light pipe. 
TABLE II. Pulse Height and Count Rate Data

\begin{tabular}{|c|c|c|c|}
\hline Section & $\begin{array}{r}\text { Pulse } \\
\text { Peak }\end{array}$ & $\begin{array}{l}\text { Maximum } \\
\text { Counts/min }\end{array}$ & $\begin{array}{c}\text { Angular } \\
\text { Position } \\
\text { on Counter }\end{array}$ \\
\hline 1 & 52.50 & 5,400 & --- \\
\hline 2 & 38.50 & 8,750 & $20^{\circ}$ \\
\hline 3 & 51.50 & 6,850 & $70^{\circ}$ \\
\hline 4 & 52.50 & 7,450 & $110^{\circ}$ \\
\hline 5 & 47.75 & 8,100 & $155^{\circ}$ \\
\hline 6 & 38.00 & 9,850 & $200^{\circ}$ \\
\hline 7 & 31.00 & 12,500 & $250^{\circ}$ \\
\hline 8 & 30.50 & 11,500 & $290^{\circ}$ \\
\hline 9 & 34.50 & 11,500 & $340^{\circ}$ \\
\hline 10 & 39.25 & 11,000 & $20^{\circ}$ \\
\hline 11 & 39.25 & 10,500 & $70^{\circ}$ \\
\hline 12 & 39.50 & 10,500 & $130^{\circ}$ \\
\hline 13 & 39.75 & 9,100 & $225^{\circ}$ \\
\hline 14 & 34.50 & 9,900 & $225^{\circ}$ \\
\hline 15 & 32.50 & 11,500 & $280^{\circ}$ \\
\hline 16 & 32.50 & 11,000 & $330^{\circ}$ \\
\hline
\end{tabular}


The differences in pulse height contributed to lowering the overall resolution of the spectrometer. Differences in efficiency would not have as great an effect upon the resolution but do effect the efficiency of the spectrometer. 


\section{SPECTROMETER PERFORMANCE}

\section{A. Response of the Basic Spectrometer Using Argon}

Although no real data were obtained using the spectrometer without the coincidence circuit, some quick preliminary tests were made. These tests indicated that it would be futile to try to get any neutron data with the simple spectrometer due to the efficiency of the large CsI crystal for gamma rays:

The spectrometer electronic equipment was adjusted with a narrow window set just above noise on the dif'terential pulse height analyzer. The pressure was varied by placing argon in the chamber to a pressure of two atmospheres and then letting the gas slowly escape to the atmosphere. An automatic recording of the count rate was taken on a Brown recorder as the chamber pressure was decreasing. The record of the count rate versus pressure curve thus obtained had no variations other than statistical variations in the count rate.

Lead and paraffin shields were tried. The lead was used first to decrease the gamma-ray background and a second quick run of the spectrum was made. Finally a paraffin shield was tried to see if any of the observed activity was due to neutrons. No change in the count rate was observed. 
Even with a thin crystal, the spectrometer as originally designed, without a coincidence set-up, does not exclude the gamma rays well enough for the neutron spectrum to be observed. It was for this reason that no attempts were made at obtaining data with the simple spectrometer and the coincidence set-up was designed and installed in the spectrometer.

B. Response of. the Coincidence Spcctrometer Using Argon

After the coincidence unit had been installed, the cosine-cubed neutron spectrometer was operated first with argon in the chamber. Argon was used in the preliminary tests because it was more abundant than the xenon for which the spectrometer had been designed. The range-energy relationship in argon does not reach a $3 / 2$ exponent until the proton energy is greater than $3 \mathrm{Mev}$. This would affect the resolution at lower energies but would not make the spectrometer inoperable. Before any neutron data were taken, the proper setting of the delay Iine had to be determined. The procedure used consisted of setting the argon pressure in the chamber at $100 \mathrm{~cm}$ of $\mathrm{Hg}$ which was calculated as being representative of the pressures to be used. Then counts of about one-half hour duration were taken at varying delay settings with the spectrometer exposed to a PoBe neutron source. The delay setting which gave the largest number of coincidence counts under these conditions was chosen as the optimum setting. This procedure resulted in a delay line setting of 0.1 microseconds. 
A rough calculation was made using the known chamber length of $16 \mathrm{~cm}$ as the range and the data of Hirschfelder and Magee ${ }^{19}$ to find the approximate position of the peaks of the PoBe neutron spectrum. The energy values for the peaks were taken from values found by Cochran and Henry $^{20}$. As counts of approximately thirty minutes were the minimum which could be used, only the region in which calculation had shown the peaks should lie'was studied. The upper energy limit was set by the leaking of the large crystal's "O" ring seal at chamber pressures above two atmospheres.

To obtain the neutron spectrum of the PoBe source, it was placed in the center of a paraffin sphere $20 \mathrm{~cm}$ in diameter. A hole from the center of the sphere with a diameter of about $2 \mathrm{~cm}$ ended about $8 \mathrm{~cm}$ from the proton radiator. The neutron beam, after leaving the collimator, had to travel through the small photo-multiplier tube and its base before it reached the proton radiator. The neutron source had a flux of $4.6 \times 10^{6}$ neutrons $/ \mathrm{cm}^{2} \mathrm{sec}$.

The study was started with $66 \mathrm{~cm}$ of $\mathrm{Hg}$ pressure, and counts were made-at-l-cm of $\mathrm{Hg}$-pressure intervals up_to_a_pressure of $171 \mathrm{~cm}$ of $\mathrm{Hg}$. A counting time of 100,000 cycles of $60 \mathrm{c} . \mathrm{p} . \mathrm{s}$. line voltage was used.

A later calculation showed that the pressure increment used was equivalent to energy increments of approximately $60 \mathrm{Kev}$. Because this

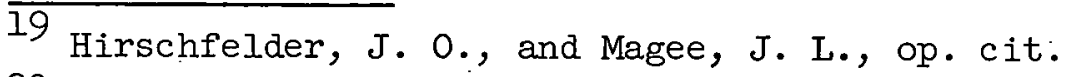

20 Cochran, R. G., and Henry, K. M., op. cit.
} 
energy increment was considerably less than the possible resolution of the spectrometer, data points were averaged in groups of four prior to plotting. The averaging process also improved the statistics by a factor of two. The resulting data from the Po-Be run using argon in the chamber are shown in Figure (10). The horizontal spread indicates the energy range over which the points was averaged and the vertical spread is the statistical variation for the average. The solid line indicates the neutron spectrum as calculated by Hess ${ }^{21}$ for the energy range observed.

It was felt that there was sufficient agreement between the experimental values and the data of Cochran and Henry ${ }^{22}$ to make continued studies using xenon in the spectrometer chamber worthwhile.

\section{C. - Response of Coincidence Spectrometer using Xenon}

Data from $a \mathrm{POB}$ and $\mathrm{a} P \mathrm{PoBe}$ neutron source were taken with xenon in the spectrometer chamber. Due to its greater atomic number, lower pressures of xenon and a smaller pressure variation were required than with argon. The pressure range for the PoBe source was from 31 to $83 \mathrm{~cm}$ of $\mathrm{Hg}$. That for the PoB source was from 5 to $80 \mathrm{~cm}$ of $\mathrm{Hg}$.

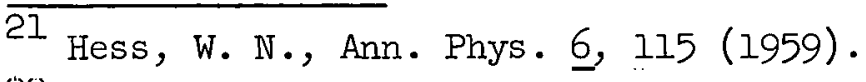

22 Cochran, R. G., and Henry, K. M., op. cit.
} 
UNCLASSIFIED

ORNL-LR- DWG. 49484

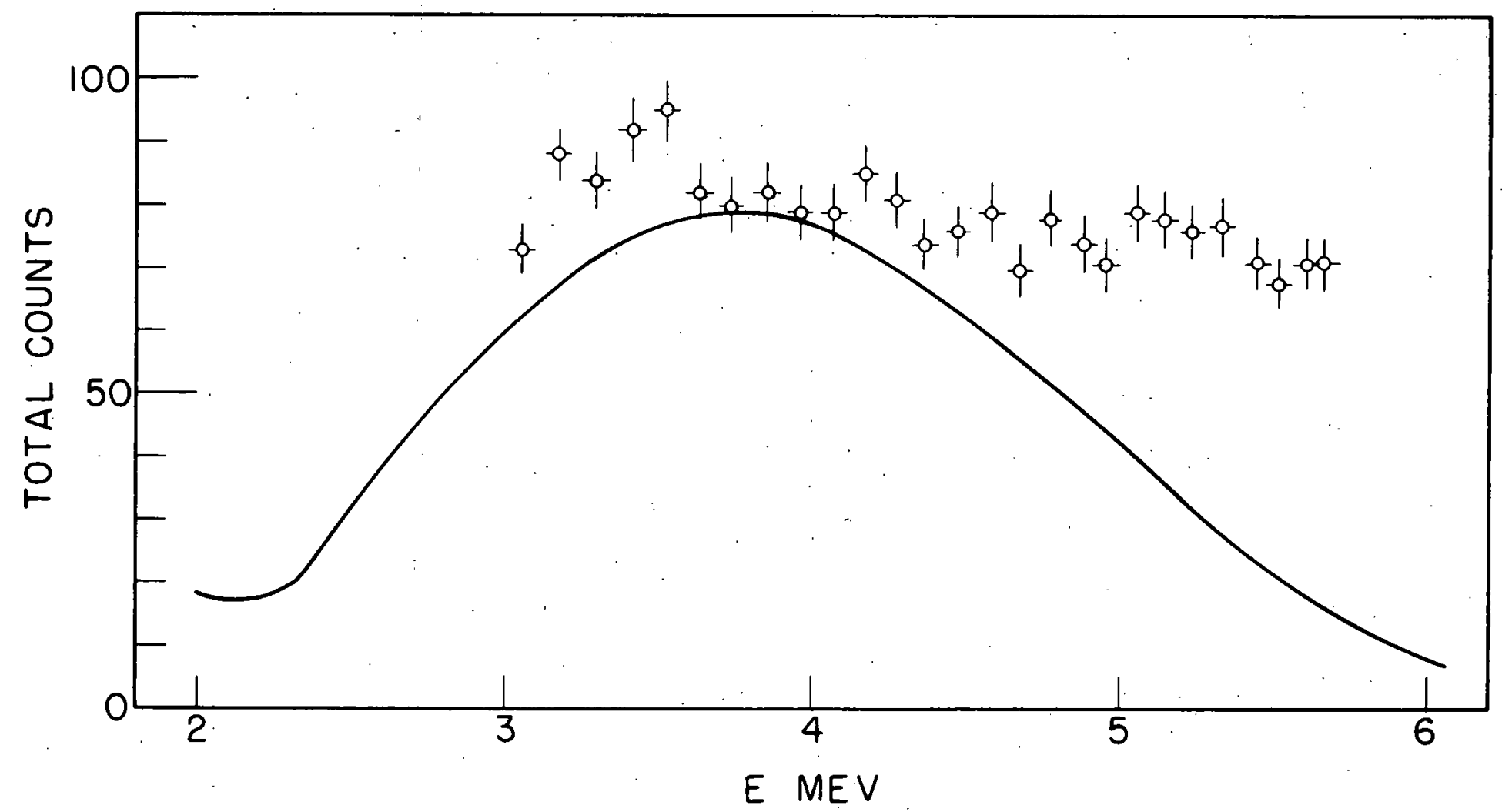

5

Fig. 10. PoBe Data with Argon in the Chamber. 
The data from both of these trials were treated in the same manner that the previous neutron data were treated. The experimental values were averaged in groups of four and the results plotted. The horizontal spread indicates the energy range over which the average was taken and the vertical spread is the statistical variation of the average. The solid lincs represent the neutron spectrum in the region of interest as calculated by Hess ${ }^{23}$. The PoBe data are shown in Figure (11) and the PoB data are shown in Figure (12).

The PoBe source had a flux of $4.6 \times 10^{6}$ neutrons $/ \mathrm{cm}^{2} \mathrm{sec}$ and was $27 \mathrm{~cm}$ from the proton radiator. The $\mathrm{PoB}$ source had a flux of $9.86 \mathrm{X}$ $10^{6}$ neutrons $/ \mathrm{cm}^{2} \mathrm{sec}$ arid was located only $9 \mathrm{~cm}$ from the proton radiator with virtually no collimation.

The PoB data suffered because it was necessary to mount the source nearer the radiator thus providing poorer collimation of the neutron beam and a higher gamma-ray background. The higher gamma-ray background increased the chance gamma coincidences sufficiently to obliterate the details of the neutron spectrum.

None of the data obtained compare favorably with the theoretical curves or with the results of previous experimenters. However, there is fair internal consistency between the data ubtained using the PoBe source with argon in the chamber and the data obtained from the same source with xenon in the chamber.

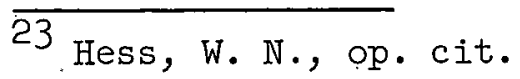


UNCL $\triangle S S I F I E D$

ORNL - LR - DWG. 49486

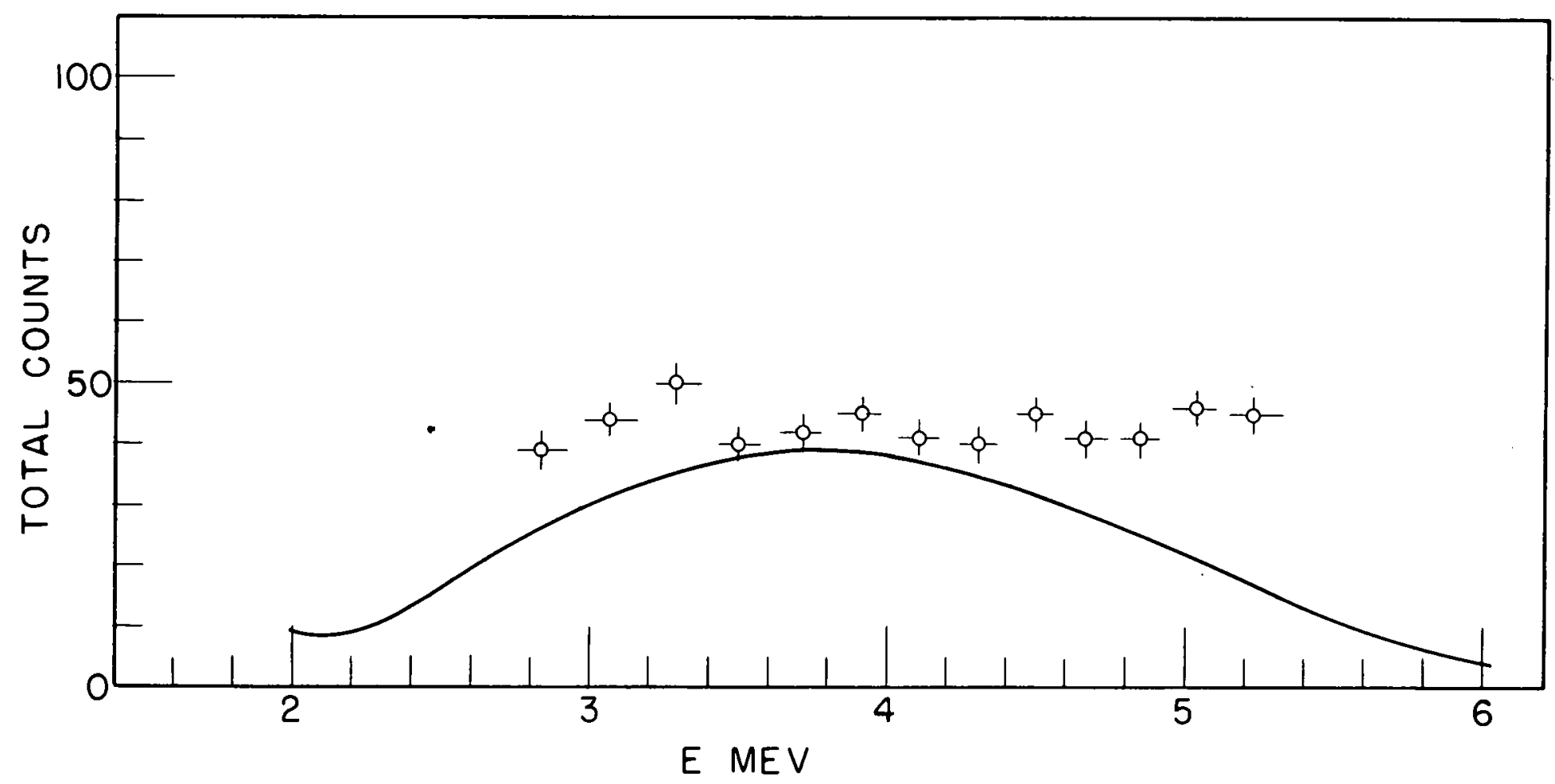

Fig. 11. PoBe Data with Xenon in the Chamber. 
is

$-v$

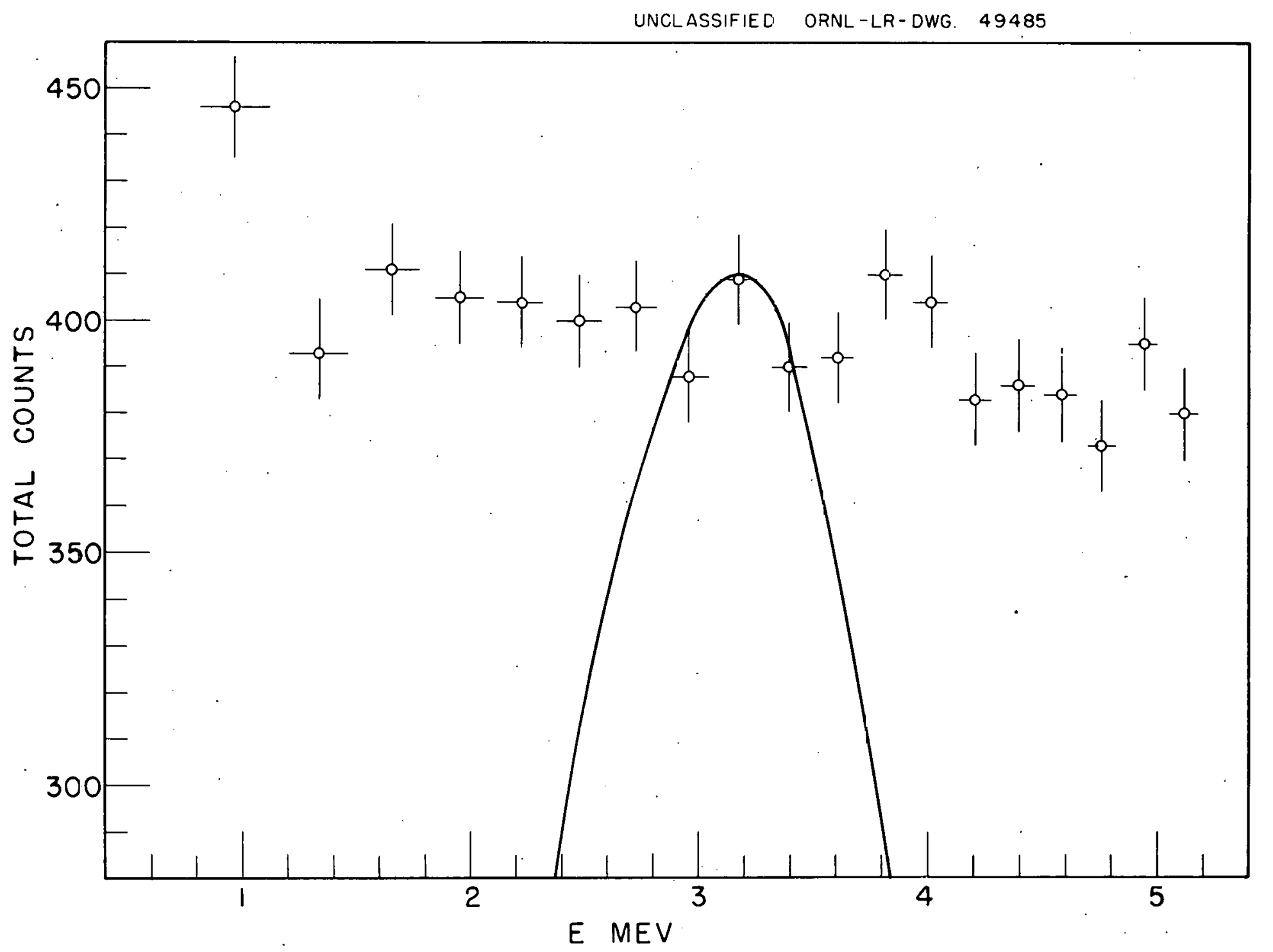

Fig. 12. Po Data with Xenon in the Chamber. 


\section{CONCLUSIONS}

The cosine-cubed neutron spectrometer was designed in an attempt to achieve a higher efficiency than had been exhibited by previous protonrecoil neutron spectrometers. The data indicate that no improvement was noted in efficiency, and that the resolution of the instrument was quite poor. Certain changes in the apparatus to improve the resolution became apparent during the course of the investigation and will be summarized briefly.

Neutrons which do not strike the radiator at a right angle cause an ambiguity in the angle-energy relationship of the recoiling protons. This ambiguity would be exhibited as a widening of the spectral lines obtained with the spectrometer. A collimator such as that used for the PoBe measurements would have a similar effect upon the measured spectrum due to the scattering in the straight throat walls of the collimator. Much of this difficulty could be overcome by the use of a collimator with a conical throat. No attempts were made to improve the neutron collimation because it was felt that the spectrum broadening caused by faulty collimation was considerably less than that caused by other difficulties.

A major factor in the loss of resolution was the large gamma-ray response experienced even when coincidence techniques were being utilized. Therefore, any means of reducing the chance gamma-ray count 
would result in an improvement of the resolution. The cosine-cubed shaped detector crystal was 1/16" thick. Calculations show that the maximum thickness necessary to completely stop all protons in the energy range of interest would be about $1 \mathrm{mil}$. Probably some phosphor such as $\mathrm{ZnS}$ would have to be used to produce a detector that thin. A reduction in crystal thickness would result in a considerable reduction in gammaray sensitivity of the large crystal. Similarly, the anthracene radiator crystal should be in the range of 30 to 40 mils thick for maximum efficiency instead of the 1/8" thickness used. The thinner radiator would also provide a reduced gamma-ray sensitivity.

A larger neutron flux would also be beneficial in two ways. First, the greater flux would improve the counting statistics and second, it would permit using a radiator crystal of smaller diameter with a subsequently better approximation of the point radiator upon which the cosine-cubed curve assumption is based. Removal of low $\mathrm{Z}$ material such as the base and socket of the small photo-multiplier tube from the neutron beam would increase the number of neutrons reaching the proton radiator. A non-hydrogenous light pipe might also help by cutting down unwanted background in the large crysta1.

Further study of Geiger's Law indicates that the Geiger function $\mathrm{g}$ which is the exponent in the range-energy relationship does not become constant but remains a slowly varying function of energy even at high energies. Calculations of $\mathrm{g}$ in the proton energy range from 1 to 
$6 \mathrm{Mev}$ show that it varies about a value of 3.1 rather than 3 for xenon. Additional calculations on various gases show that $g$ is the most constant for xenon. This basic deficiency in the theory of the cosinecubed neutron spectrometer would cause a decrease in resolution of the device.

Even if corrections for all these deficiencies could be made, it is doubtful if this spectrometer would have any real advantage over previously designed proton-recoil neutron spectrometers. While this instrument should have had an efficiency of $10^{-4}$ protons per neutron, calculations from the experimental results indicate an efficiency of $10^{-5}$ protons per neutron. An efficiency of $10^{-5}$ protons per neutron is comparable to that obtained from earlier proton-recoil neutron spectrometers. Even if the maximum efficiency had been observed this single channel device would not have been more advantageous than a less efficient spectrometer capable of multichannel operation. 
Bethe, H., HANDBUCH DER PHYSIK, "Quantenmechanick der Ein und ZweiElectronenproblems", Volume 24, Part I (Verlag Von Julius Springer, Berlin, 1933) p. 521.

Calvert, J. M., Jaffe, A. A., and Maslin, E. E., "An Investigation of the Reaction $F^{19}(d, n) \mathrm{Ne}^{20}$ Using a New Fast Neutron Spectrometer", Proc. Phys. Soc. (London) A-68, 1017 (1955).

Cochran, R. G., and Henry, K. M., "Proton Recoil Fast Neutron Spectrometer. Part II", Rev. Sci. Instr. 26, 757 (1955).

Hess, W. N., "Neutrons from $(\alpha, n)$ Sources", Ann. Phys. 6, 115 (1959).

Hill, D. L., "The Neutron Energy Spectrum from U ${ }^{235}$ Thermal Fission", Phys. Rev. 87, 1034 (1952).

Hirschfelder, J. O., and Magee, J. L., "Range-Energy Relations for Protons in Substances Containing $\mathrm{C}, \mathrm{H}, \mathrm{O}, \mathrm{A}$, and Xe", Phys. Rev. 73, 207 (1948).

Holt, J. R., and Litherland, A. E., "A Fast Neutròn Spectrometer", Rev. Sci. Instr. 25, 298 (1954).

Hurst, G. S., et al., "Fast Neutron Spectrometer", ORNL-2049, page 54 (1956).

Johnson, C. H., and Trail, C. C., "Proton Recoil Neutron Spectrometer", Rev. Sci. Instr. 27, 468 (1956).

Marshall, J., "6BN6 Fast Coincidence Circuit", Nucleonics 10, (1952).

Mozely, R. F., and Shoemaker, F. C., "A Fast Neutron Scintillation Spectrometer", Rev. Sci. Instr. 23, 569 (1952).

Nereson, N., and Darden, S., "Average Neutron Total Cross Section in the 3 to 12 Mev Region", Phys. Rev. 89, 775 (1953).

Perlow, G. J., "Recoil Type Neutron Spectrometer for 0.05 to 1 Mev", Rev. Sci. Instr. 27, 460 (1956). 
Reid, G. C., "Energy Levels in $\mathrm{B}^{10}$ and $\mathrm{Be}^{8}$, Proc. Phys. Soc. (London), A-67, 466 (1954).

Ribe, F. L., and Seagrave, J. D., "The Pickup Reactions $B^{10}(n, d) B e^{9}$ for 14 Mev Neutrons", Phys. Rev. 98, 934 (1954).

Risser, J. R., Price, J., and Class, C.M., "Angular Distribution of Resolved Neutron Groups from the $B^{l l}(d, n) C^{12}$ Reaction", Phys. Rev. 98, 1183(A) (1955).

Schmidt-Rohr, U.; "Ein Spektrometer fir schnelle Neutronen un das Neutronenspektrum von $\mathrm{Ra}+\mathrm{Be} "$, Z. Naturforsch, 8a, 470 (1953).

Watt, B. E., "Energy Spectrum of Neutrons from Thermal Fission of $U^{235}$, Phys. Rev. 87, 1037 (1952). 


\author{
ORNL-2969 \\ UC-34 - Physics \\ TID-4500 (16th ed.)
}

\title{
INTLERNAL DISTRIBUTION
}

1. C. E. Center

2. Biology Library

3. Health Physics Library

4-5. Central Research Library

6. Reactor Division Library

7-26. Laboratory Records Department

27. Laboratory Records, ORNL R.C.

28. J. P. Murray $(\mathrm{K}-25)$

29. R. G. Jordan $(Y-12)$

30. A. M. Weinberg

31. J. A. Swartout

32. E. D. Shipley

33. M. L. Nelson

34. K. Z. Morgan

35. S. C. Lind

36. A. S. Householder

37. C. S. Harrill

38. C. E. Winters

39. A. H. Snell

40. E. H. Taylor

41. W. H. Jordan

42. T. A. Lincoln

43. A. Hollaender

44. F. I. Culler

45. H. E. Seagren

46. D. Phillips

47. M. T. Kelley

48. E. E. Anderson

49. R. S. Livingston

50. C. P. Keim

51. K. E. Cowser

52. C. D. Susano

53. L. B. Farabee

54-78. F. J. Davis

79. R. J. Morton

80. C. E. Haynes

81. E. G. Struxness .

82. W. E. Cohn

83. H. H. Hubbell, Jr.

84. D. E. Arthur

85. J. Neufeld

86. M. J. Skinner

87. J. C. Hart

88. T. H. J. Burnett

89. W. J. Lacy

90-99. G. S. Hurst

100. T. E. Bortner

101. J. A. Lane

102. P. M. Reyling

103. L. B. Holland

104. J. I. Gabbard

105. R. A. Charpie

106. D. M. Davis

107. P. E. Erown

108. E. D. Gupton

109. J. C. Ledbetter

110. R. L. Clark

111. G. C. Cain

112. L. C. Johnson

113. W. W. Ogg

114. O. D. Teague

115. E. I. Sharp

116. E. J. Kuna

117. H. H. Abee

118. C. R. Guinn

119. A. D. Warden

120. C. C. Sartain

121. J. R. Muir

122. J. A. Auxier

123. M. F. Fair

124. S. I. Auerbach

1.25. G. W. Royster

126. R. S. Cockreham

127. F. W. Sanders

128. F. C. Mainenschein

129. W. J. Boegly, Jr.

130. F. L. Parker

131. W. E. Lotz

132. B. Fish

133. M. B. Edwards

134. F. M. Empson

135. G. G. Robeck 
136. R. D. Birkhoff

137. R. H. Ritchie

138. J. A. Harter

139. R. M. Johnson

140. J. S. Cheka

141. P. N. Hensley

142. R. W. Peelle

143. D. R. Nelson

144. E. B. Wagner

145. W. Kofink

146. C. A. Preskitt
147-171. P. W. Reinhardt

172-196. J. H. Thorngate

197. J. C. Frye (consultant)

198. W. H. Langham (consultant)

199. R. I. Platzman (consultant)

200. L. S. Taylor (consultant)

201. G. M. Fair (consultant)

202. R. E. Zirkle (consultant)

203. ORNL - Y-12 Technical Library, Document Reference Library

\section{EXTERNAL DISTRIBUTION}

204. Knolls Atomic Power Laboratory, Schenectady (R. J. Feinberg)

205. Division of Research and Development, AEC, ORO

206-833. Given distribution as shown in TID-4500 (16th ed.) under Physics category (75 copies - OTS) 